\title{
Modal participation of fixed-fixed single-walled carbon nanotube with vacancies
}

\author{
M. A. Eltaher ${ }^{1,2} \cdot$ T. A. Almalki ${ }^{1,2,3,4} \cdot$ K. H. Almitani ${ }^{1} \cdot$ K. I. E. Ahmed ${ }^{1,3} \cdot$ A. M. Abdraboh ${ }^{4}$
}

Received: 17 December 2018 / Accepted: 19 February 2019 / Published online: 25 February 2019

(c) The Author(s) 2019

\begin{abstract}
This article presents an investigation of dynamical behaviors of perfect and defected fixed-fixed single-walled carbon nanotube (SWCNTs) model as a beam structures. The fundamental frequencies and modal participation factors for fixed-fixedsupported SWCTS are considered through this analysis for the first time. Energy-equivalent model is implemented to find a relationship between the energy stored in atomic chemical bonding and potential energy of mechanical beam structure. Nanotube software modeler is exploited to create a geometrical structural of SWCNTs by defining its length of nanotube, bond distance between two atoms, and chiral angle. The tube of SWCNTs are simulated as fixed-fixed-supported structure at both ends, while bonding between each two atoms is modeled by 3D beam element with circular cross section. Parametric results are illustrated to display the effects of vacancy on activation and deactivation of vibration modes, fundamental frequencies, and modal participation factors of SWCNTs.
\end{abstract}

Keywords Free vibrations · Modal participation factors · Energy-equivalent model · Defected SWCNTs · Finite-element analysis $\cdot$ ANSYS mechanical APDL

\section{Introduction}

From 1991 till now, Carbon nanotubes (CNTs), discovered by Sumio Ijima, have huge amount of scientific research from numerous fields (i.e.; material science, mechanical science, chemistry, and physics sciences) and real applications (i.e.; nano-electronics, nano-switch, solar cell, medical tools, and nano-devices). CNT is the strongest material known until now, with astonishing mechanical properties (Eltaher et al. 2016).

M. A. Eltaher

meltaher@kau.edu.sa; mmeltaher@zu.edu.eg

1 Mechanical Engineering Department, Faculty of Engineering, King Abdulaziz University, P.O. Box 80204, Jeddah, Saudi Arabia

2 Mechanical Design and Production Department, Faculty of Engineering, Zagazig University, P.O. Box 44519, Zagazig, Egypt

3 Mechanical Engineering Department, Assiut University, P.O. Box 71615, Assiut, Egypt

4 Physics Department, Faculty of Science, Banha University, Banha, Egypt
To comprehend mechanical behaviors of CNTs, the experimental and theoretical studies (i.e.; atomistic modeling, molecular simulation, and advanced continuum mechanics) are exploited. Krishnan et al. (1998) assessed the modulus of elasticity of SWCNTs using TEM. Salvetat et al. (1999) exploited AFM to evaluate shear and elastic moduli of SWNT ropes, which are in the order of $1 \mathrm{GPa}$ and $1 \mathrm{TPa}$, respectively. They found that low inter-tube shear effect controls the flexural deformation of SWNTs. Charlier (2002) investigated, theoretically, the effects of different types of imperfections, such as vacancies, or dopant on the electronic properties of CNTs. He concluded that vacancies drastically modify the electronic behaviors and characteristics of those nano-systems. Mielke et al. (2004) exploited the quantum mechanical theory and Tersoff-Brenner potential of molecular mechanics (MM) to explore the effects of vacancies and holes defects in the fracture of SWCNTs. Ma et al. (2004) studied magnetic behaviors of vacancies in graphene and SWCNTs using spin-polarized density functional theory.

Wang and Varadan (2006) investigated the wave characteristics in CNTs, which was proposed from the discrete atomic nature, via beam theories. They recommended the Timoshenko beam model to analyze a wave transition in SWCNTs in case of terahertz frequency range. Soltani 
et al. (2012) considered transverse vibrations of light axial waviness of SWCNT. They considered tube as a thin and thick beam, and so, they modeled it by Euler-Bernoulli and Timoshenko theories. Gajbhiye and Singh (2015) proposed different techniques including a potential of Tersoff-Brenner to study the vibration behaviors of open-end and cappedend of SWCNTs. They concluded that zigzag and armchair structures display akin vibration features at lower vibration modes, and different dynamical features at very high resonant frequencies. Zemri et al. (2015) exploited nonlocal Eringen and higher order shear beam theory to study the mechanical behaviors of FG nanobeams. Chaht et al. (2015) addressed static bending and static stability buckling behaviors of nonlocal FG nano-scale beams considering the effect of thickness stretching. Belkorissat et al. (2015) developed a new hyperbolic plate theory to study the vibrations of FG nonlocal Nano-scale plate. Eltaher and Agwa (2016) studied theoretically the vibration behaviors of SWCNTs carrying a concentrated mass under pretension. The study presented that the SWCNT resonator can sense a very minute mass weighting $10^{-1}$ zeptogram. Eltaher et al. (2016) examined material and size dependencies' effects on nonlinear bending behavior of CNTs by energy-equivalent model. Ahouel et al. (2016) exploited both nonlocal Eringen and trigonometric shear theory to study mechanical behaviors of FG nonlocal Eringen nanobeams as well as neutral axis effects. Tahouneh et al. (2016) investigated the material properties of nanocomposites reinforced by CNT arrays using the representative volume element (RVE). Agwa and Eltaher (2016) developed the modified continuum approach to examine the impacts of surface energy and surface tension on flexural vibrations frequencies of nano-mass sensor using carbyne materials. Bellifa et al. (2017) suggested zero shear theory to investigate the nonlinear postbuckling of nano-scale Eringen beams considered the axial displacement. Bouafia et al. (2017) examined the size and stretching effects on static transverse bending and flexural vibration of FG nonlocal nano-scale beams implemented by the quasi-3D shear theory. Bounouara et al. (2016), Khetir et al. (2017), and Besseghier et al. (2017) employed zero shear and refined trigonometric shear theories to analyze buckling and vibration of FG nonlocal Eringen nano-plates attached with an elastic media. Mouffoki et al. (2017) presented the vibration behaviors of nonlocal hygro-thermal nanobeams modeled by two-unknown trigonometric shear deformation beam theory. Karami et al. (2017) studied tri-axial magnetic effects on wave propagations of anisotropic nonlocal-strain-gradient nano-plates.

Yazid et al. (2018) exploited two-variable refined plate to investigate static buckling of graphene orthotropic nanoplates rested on elastic medium. Eltaher et al. (2018a, b) exploited energy-equivalent model and modified coupled stress to discover vibrational characteristics of SWCNTs modeled as a beam structure. The impact of size-parameter, chiral vector translation indices, and orientation on the vibration behaviors are illustrated. Mokhtar et al. (2018) and Kadari et al. (2018) analyzed the buckling behavior of graphene sheet modeled by nonlocal Eringen differential form and simple shear plate theory. Bouadi et al. (2018) investigated critical buckling forces of graphene sheets that modeled by nonlocal higher order shear deformation theory. Esbati and Irani (2018) exploited stochastic finite-element methods to evaluate structural reliability and probabilistic fracture properties of CNTs. Hamza-Cherif et al. (2018) illustrated thermal effects on vibration of SWCNT nanobeam surrounded by an elastic foundation. Shahabodini et al. (2018) developed a numerical multiscale analysis to study the vibrations of SWCNTs modeling its kinematics membrane by Cauchy-Born rule. Bianco et al. (2018) developed the complete formulation of linear stiffness matrices, which is practiced in beam theory under constant and/or linear loading distribution in the longitudinal direction. Karami et al. $(2018 \mathrm{a}, \mathrm{b})$ exploited a nonlocal-strain-gradient on higher order shell structural model to predict the mechanical characteristics and waves of anisotropic nano-shells. Vila et al. (2018) deliberated the effects of axial and transverse coupling on nonlinear vibrations of one-dimensional solid structures using inertia gradient continuum model. Ahmadabadi et al. (2018) illustrated the thermal dependence of zigzag SWCNT diameter on the state of its density. Bakhadda et al. (2018) analytically examined bending and vibration response of four types of distributions of uniaxial-aligned CNT-reinforced plates rested on the Pasternak foundation by hyperbolic shear theory. Eltaher et al. (2019) exploited equivalent-continuum mechanics approach and finite-element method to characterize the mechanical behaviors of SWCNTs. Eltaher et al. (2019) studied the nonlinear postbuckling behaviors of curved carbon nanotubes using energy-equivalent model and Euler-Bernoulli beam kinematic relations.

Nevertheless, CNTs are, perhaps, not like completely perfect structures as they are once supposed to be. Imperfections like vacancies and/or dopant extremely change the mechanical, electrical, and chemical properties of CNTs. Most of the previous studies considered the defects effect using only molecular simulations. The current paper propose a modified continuum mechanics model with finite-element simulation to present the effects of vacancies on the vibration behaviors and modal participation factors of fixed-fixed SWNCT. Sound effects of vacancy on deactivation and activation of mode shapes are presented for the first time for fixed-fixed-supported CNT structures. Coupled modes and uncoupled modes are also investigated and presented. The atomic bond between adjacent atoms is modeled as beam element. The energy-equivalent model is recommended to extract the equivalent mechanical energy of the structure with that in the chemical bond between atoms. 
Nanotube modeler is exploited to create a geometrical structure of CNTs to be impeded into the finite-element model to extract the modal participation factors and the vibration behaviors of these structures. Different orientation of CNTs, such as armchair and zigzag, are studied. Effect of tube length is also presented.

\section{Geometrical structural of SWCNTs}

Carbon nanotube, which is layer of graphene sheet wrapped into cylindrical shape with a diameter about $1 \mathrm{~nm}$ and a length up to many micrometers, is controlled by chiral angle orientation and tube diameter. The vector used to depict a chiral angle is as follows:

$\vec{C}_{h}=n \vec{a}_{1}+m \vec{a}_{2}$,

in which $\vec{a}_{1}$ and $\vec{a}_{2}$ are basis vectors. An integer pair $(n, m)$ is used to specify structure orientation of CNTs, as presented in Fig. 1. The lattice basis vectors in Cartesian coordinates can be portrayed by the following:

$\vec{a}_{1}=\left(\frac{\sqrt{3 a}}{2}, \frac{a}{2} a\right), \quad \vec{a}_{2}=\left(\frac{\sqrt{3 a}}{2},-\frac{a}{2}\right)$,

where $a=\sqrt{3} a_{\mathrm{c}-\mathrm{c}}$, is the lattice constant, and $a_{\mathrm{c}-\mathrm{c}}=1.42 \AA$ is the bond length. In case of $n=m$, the nanotube is called armchair structure. If $m$ is equal to zero, SWCNT is called

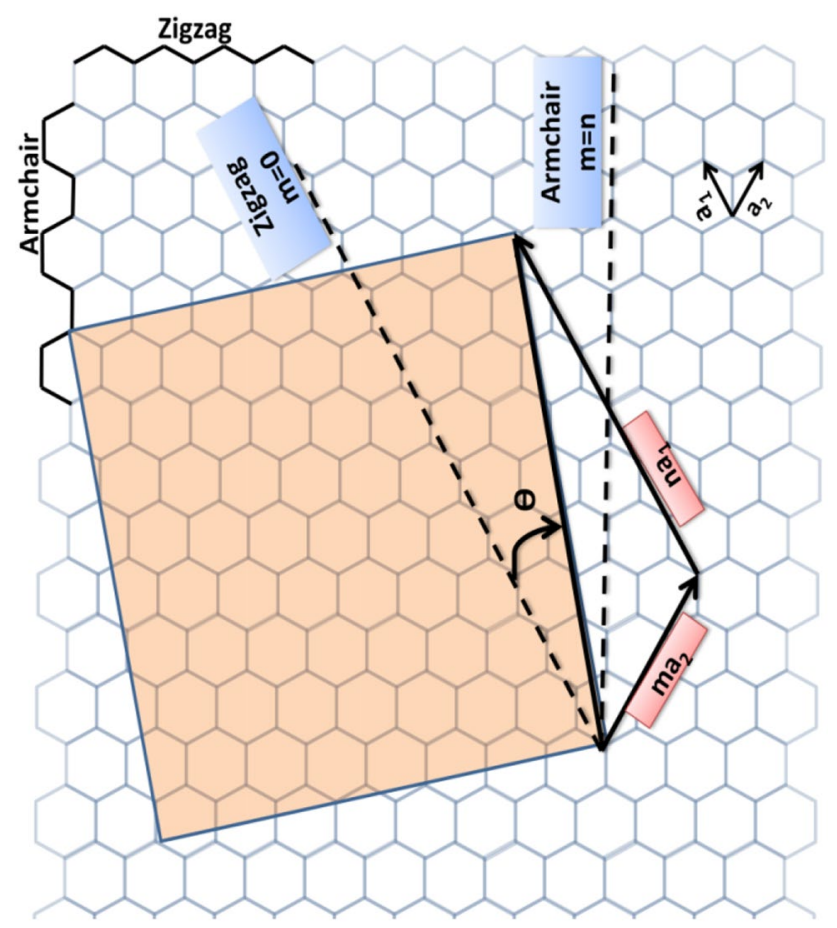

Fig. 1 Hexagonal lattice of graphene sheet and its orientations and basis vectors a zigzag structure. Elsewhere, the nanotube is donated as chiral structure. Figure 2 shows three possible orientations of CNTs structure. Figure 2 a represents the orientation of graphene sheets before rolling, whereas Fig. $2 b$ shows the structure of grapheme sheet after rolling to NTs.

The relationships among nanotube diameter $\left(d_{\mathrm{nt}}\right)$ and lattice vectors basis can be represented by the following:

$d_{\mathrm{nt}}=a \sqrt{n^{2}+m^{2}+n m}$.

The relationships between chiral angle $\left(\theta_{\mathrm{ch}}\right)$ and lattice vectors basis can be described as follows:

$\theta_{\mathrm{ch}}=\cos ^{-1}\left(\frac{2 n+m}{2 \sqrt{n^{2}+m^{2}+n m}}\right)$.

In case of zigzag and armchair orientations, the diameter of nanotube can be calculated by $d_{t}=\frac{\sqrt{3} n a}{\pi}$, and $d_{t}=\frac{3 n a}{\pi}$, respectively. Note the chiral angle in zigzag $=0$, while the chiral angle in the armchair $=30$. This is the maximum angle, after which the NT structure begins to repeat its orientation.

\section{Chemical energies vs mechanical energies}

To get a relationship between microscopic chemical energies of CNTs and their corresponding macroscopic mechanical energies, covalent bonding among carbon's atoms is represented by a force filed. The force filed is represented by a potential energy of chemical bond $U_{\mathrm{ch}}$ as follows (Rappé et al. 1992):

$U_{\text {ch }}=U_{L}+U_{\theta}+U_{T}+U_{\omega}$,

where $U_{L}$ is bond-stretching energy, $U_{\theta}$ is angle variation energy, $U_{T}$ is torsion energy, and $U_{\omega}$ is inversion energy.

When SWCNTs exposed to tension loads and transverse bending load in the 2D plane analysis, the most substantial energies included are bond-stretching and angle energies, and others can be neglected. Consequently, Eq. (5) can be reduced to the following ( $\mathrm{Wu}$ et al. 2006; Shokrieh and Rafiee 2010; Eltaher et al. 2019):

$U_{\mathrm{ch}}=U_{L}+U_{\theta}=\frac{1}{2} \sum_{i} K_{i}\left(\mathrm{~d} R_{i}\right)^{2}+\frac{1}{2} \sum_{j} C_{i}\left(\mathrm{~d} \theta_{i}\right)^{2}$,

where $K_{i}$ is the stretching spring parameter, $\mathrm{d} R_{i}$ is the element of stretching, $C_{i}$ is the rotational spring parameter, $\mathrm{d} \theta_{i}$ is the element of rotation angle, and $i$ is corresponding to the bond number.

By assuming that, the chemical covalent bond can be represented by beam structure, and based on continuum mechanics, the total energy stored in beam element can be composed 

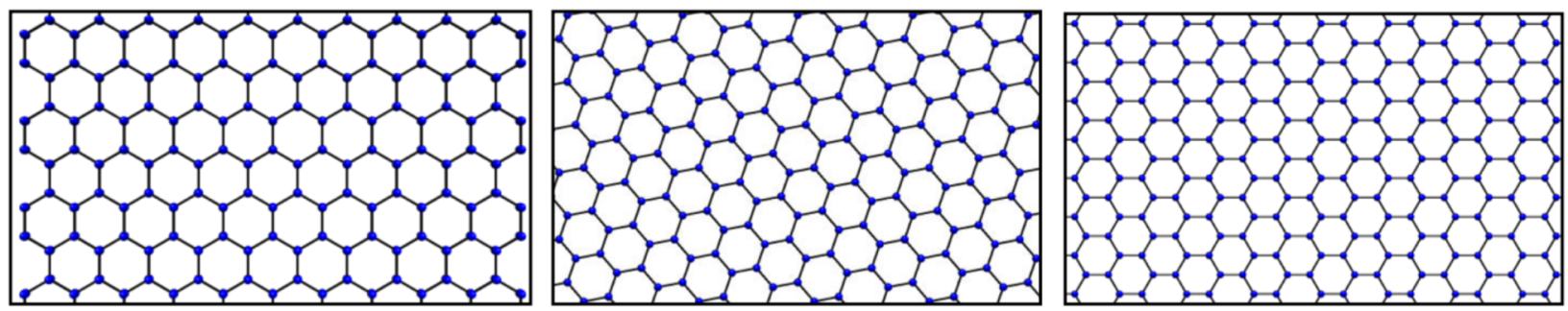

(a) Graphene sheets before rolling
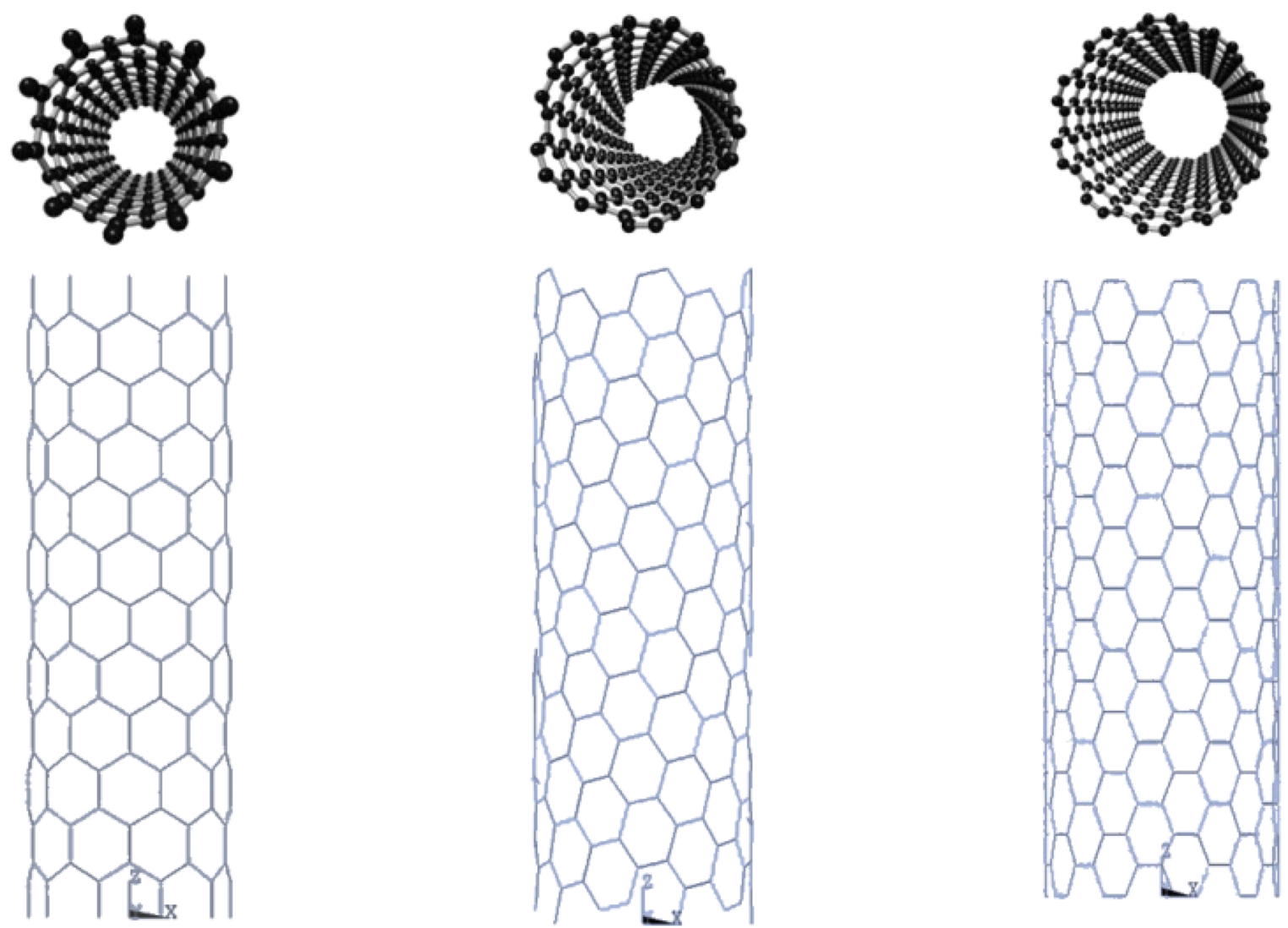

Zigzag

Chiral

Armchair

(b) Graphene sheets after rolling

Fig. 2 Three possible structure orientation of SWCNTs

mainly from tension and bending deformations. Hence, the total mechanical energy of a beam is depicted by the following:

$U_{m}=U_{T}+U_{b}=\frac{1}{2} \frac{E A}{L}(\Delta L)^{2}+\frac{1}{2} \frac{E I}{L}(2 \alpha)^{2}$,

where $E$ corresponds to Young's modulus, $L$ is the beam length, $A$ is the beam cross-sectional area, $I$ is the beam area moment, $\Delta L$ is the stretching length, and $2 \alpha$ is the rotation angle due to bending moment. By equating chemical energy in single atom-atom bond described in Eq. (6) with Eq. (7) of total energy of the beam, it can be concluded that:

$K_{i}=\frac{E A}{L} \quad$ and $\quad C_{i}=\frac{E I}{L}$. 
Since the bond is circular cross-sectional, the geometrical parameters of the bond can be calculated by the following:

$A=\frac{\pi d^{2}}{4} \quad$ and $\quad I=\frac{\pi d^{4}}{64}$.

Substitute Eq. (9) into Eq. (8), the bonding diameter $(d)$ and $E$ modulus of equivalent beam element are as follows:

$d=4 \sqrt{\frac{C_{i}}{K_{i}}}$ and $E=\frac{\left(K_{i}\right)^{2}}{4 \pi C_{i}}$.

\section{Dimension modification}

In general, finite-element analysis of beam structure is insensitive to geometrical scale of nanometer in its analysis. Therefore, some adaptations from nano-scale to macro-scale units must be prepared before entering the input data into the finite-element model. Therefore, the following transformations have been implemented (Table 1).

\section{Numerical results}

\section{Validation}

First, the main core of this section is to confirm that the methodology of the present study is on the right track. The methodology in Gajbhiye and Singh (2015) represents carbon nanotubes as beam element and mass element using the ANSYS program. The same methodology is used in the current work without using mass elements. Fixed-fixed boundary conditions for $\operatorname{CNT}(5,5)$ are

Table 1 Modified dimensions for the finite-element model software

\begin{tabular}{llll}
\hline Division & Units & $\begin{array}{l}\text { Original } \\
\text { dimensions }\end{array}$ & $\begin{array}{l}\text { Finite- } \\
\text { element } \\
\text { dimensions }\end{array}$ \\
\hline Length & $\mathrm{m}$ & $L$ & $10^{10} L$ \\
Density & $\mathrm{kg} / \mathrm{m}^{3}$ & $\rho$ & $10^{-4} \rho$ \\
Young's modulus & Pascal & $E$ & $E$ \\
Shear modulus & Pascal & $G$ & $G$ \\
Frequency & Hertz & $f$ & $10^{-8} f$ \\
\hline
\end{tabular}

proposed. The material properties of CNTs are Young's modulus $E=21.607 \times 1012 \mathrm{~Pa}$, Poisson ratio $v=0.28$, and density $=1.9 \mathrm{~kg} / \mathrm{m}^{3}$. The geometric properties are: $L=69.29$ $\AA, d=0.716 \AA, t=3.4 \AA$, and $a_{\mathrm{c}-\mathrm{c}}=0.145 \mathrm{~nm}=1.45 \AA$. as represented by Gajbhiye and Singh (2015).

The first seven fundamental frequencies of armchair nanotube $(5,5)$ are demonstrated in Table 2 . As observed, the current results do not agree with that obtained by Gajbhiye and Singh (2015) with a maximum difference of $12.5 \%$ at fifth mode. This difference occurs, because the current model uses 3D beam element with uniformly distributed mass; however, Gajbhiye and Singh (2015) assumed the CNT as elastic beam with lumped carbon masses at tits two ends.

\section{Effect of defect position of SWCNT}

This section is devoted to illustrating the effect of defect position on fundamental frequencies and modal participation factor in case of zigzag and armchair orientations. Two defected positions are proposed, which are at one of the fixed ends titled with side defect and at the middle of the tube titled with middle defect, as shown in Fig. 3. A zigzag (10, $0)$ and armchair $(10,10)$ orientations are supported from both sides for fixed-fixed configuration. Figure 3 illustrates the prefect and imperfect (defected) configurations of CNT in case of zigzag and armchair orientations.

3D beam element is exploited to describe and simulate the $\mathrm{C}-\mathrm{C}$ bond, with the following geometrical properties $d=0.716 \AA, t=3.4 \AA, a_{\mathrm{c}-\mathrm{c}}=0.145 \mathrm{~nm}=1.45 \AA$, and $0.34 \mathrm{~nm}$ wall thickness, (Rappé et al. 1992) and the following material properties: $E=5.49 \mathrm{E} 12 \mathrm{~Pa}, v=0.3$, and density $=1.7 \mathrm{~kg} /$ $\mathrm{m}^{3}$. The overall length of SWCNT is $50 \AA$.

\section{(a) Zigzag-capped SWCNT $(10,0)$}

Table 3 illustrates the effect of defect location on the first ten natural frequencies and the modal participation factors for Zigzag $(10,0)$ SWCNTs. It is worth noting that the first and second natural frequencies are equal in their values, but have different modal participation in case of prefect tube (un-defected). The defected conditions show significant changes in the first and second frequencies and their values become unequal. The modal participation is affected in case of side defect; however, the middle defect has no effect on
Table 2 First seven frequency values $f$ (THZ) for capped CNT $(5,5)$ with CNT length $L=69.29 \AA$

\begin{tabular}{llllllll}
\hline Frequency no. & 1 & 2 & 3 & 4 & 5 & 6 & 7 \\
\hline $\begin{array}{l}\text { Gajbhiye and Singh } \\
\text { (2015) }\end{array}$ & 0.046 & 0.046 & 0.261 & 0.261 & 0.347 & 0.597 & 0.646 \\
Present & 0.042 & 0.042 & 0.248 & 0.248 & 0.390 & 0.619 & 0.645 \\
Difference (\%) & 9.916 & 9.896 & 4.879 & 4.864 & 12.508 & 3.605 & 0.155 \\
\hline
\end{tabular}


Fig. 3 Perfect, side defect, and middle defect (vacancy) of SWCNT with $50 \AA$ length
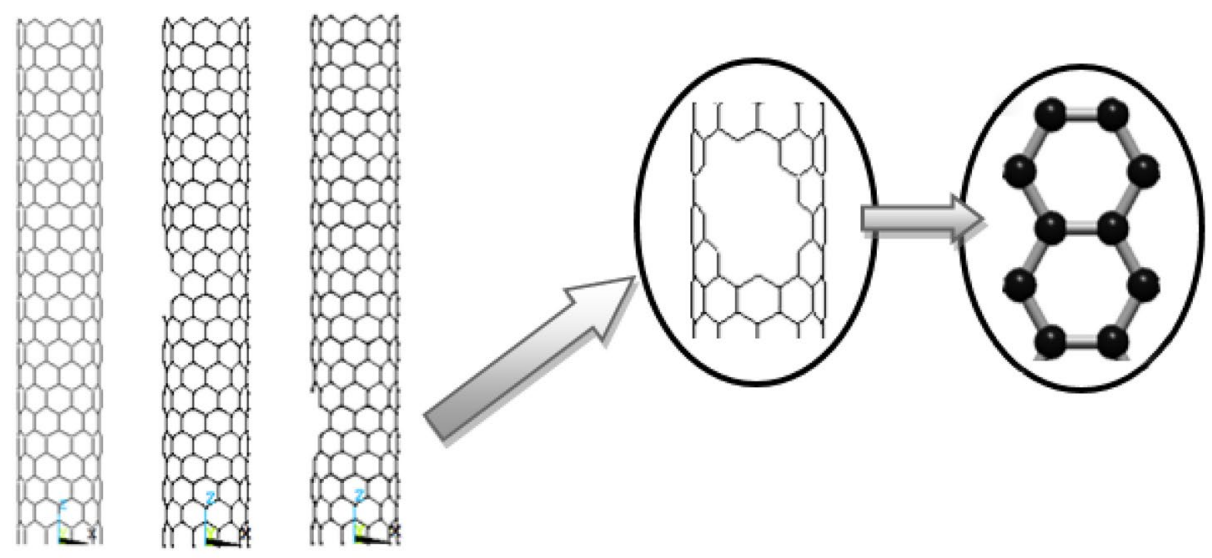

(a) 50 A length of Zigzag $(10,0)$ with defects

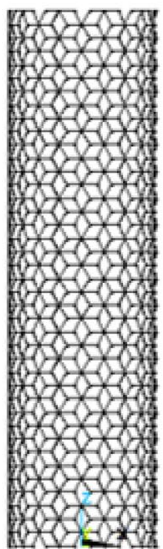

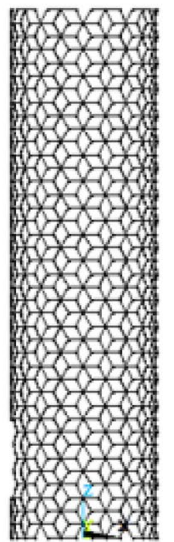

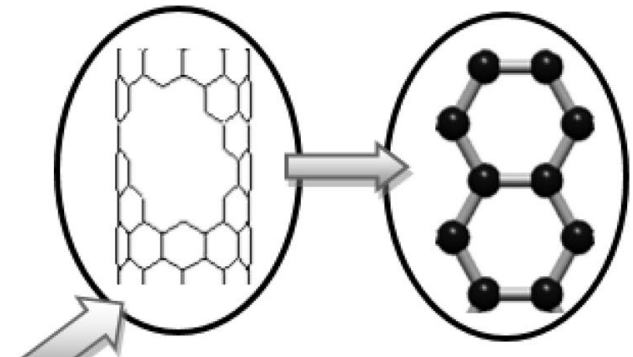

(b) 50 Å length of armchair $(10,10)$ with defects

Table 3 The first ten frequency values $f(\mathrm{GHz})$ for zigzag CNT $(10,0)$ with CNT length $L=50 \AA$

\begin{tabular}{lllllllllll}
\hline & 1 & 2 & 3 & 4 & 5 & 6 & 7 & 8 & 9 & 10 \\
\hline Mode of vibration & $\mathrm{UY} \& \mathrm{RX}$ & $\mathrm{UX} \& \mathrm{RY}$ & $\mathrm{RZ}$ & $\mathrm{RX}$ & $\mathrm{RY}$ & $\mathrm{UZ}$ & $\mathrm{UY}$ & $\mathrm{UX}$ & Weak & Weak \\
Perfect & 304.63 & 304.63 & 610.80 & 669.68 & 669.68 & 1036.00 & 1101.20 & 1101.20 & 1223.50 & 1226.10 \\
Mode of vibration & $\mathrm{UY} \& \mathrm{RX}$ & $\mathrm{UX} \& \mathrm{RY}$ & $\mathrm{RZ}$ & $\mathrm{RZ}$ & $\mathrm{RX}$ & $\mathrm{UZ}$ & Weak & Weak & Weak & Weak \\
With middle defect & 308.63 & 325.68 & 647.22 & 661.78 & 707.42 & 1066.00 & 1086.90 & 1134.30 & 1155.30 & 1196.20 \\
Mode of vibration & $\mathrm{UX} \& \mathrm{RY}$ & $\mathrm{UY} \& \mathrm{RX}$ & $\mathrm{RZ}$ & $\mathrm{RX}$ & $\mathrm{RY}$ & $\mathrm{UZ}$ & $\mathrm{UX}$ & Weak & Weak & Weak \\
With side defect & 300.39 & 318.74 & 606.38 & 696.06 & 714.57 & 1006.30 & 1137.90 & 1153.50 & 1205.90 & 1225.00
\end{tabular}

the first two mode shapes. The third frequency increases from 610.80 to $647.22 \mathrm{GHz}$ as defect occurs in the middle and decreases to 606.38 in case of side defect. However, their modal participation is not affected by the defect. As shown in Table 3, the middle defect is more significant on the fundamental frequencies than the side defect, which has the same value of natural frequencies at higher level with perfect tube.

The modal participation factor for the perfect and the two defected tubes are shown in Fig. 4. In case of free defect zigzag SWCNTs, the modal participation with displacement in $X$-DIR (UX) is dominant in both second and third modes. The modal participation with displacement in $Y$-DIR (UY) is dominant in both first and seventh modes. However, the modal participation with displacement in $Z$-DIR (UZ) is mostly dominant in sixth mode. The modal participation with rotational around $x$-axis (RX), $y$-axis (RY), and $z$-axis (RZ) are dominant in the first, second, and third modes, respectively. 


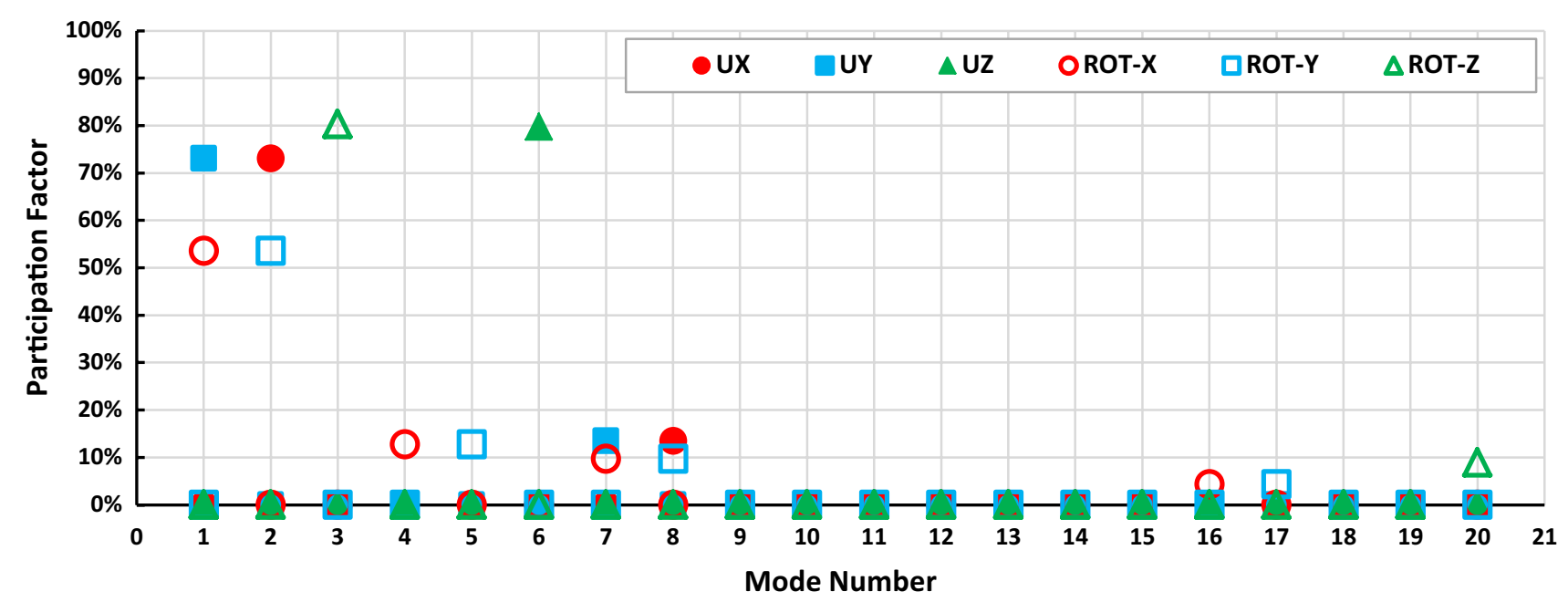

Fig. 4 Modal participation factor for zigzag $(10,0)$ CNT without defect (length $=50 \AA$ )

The modal participation factors in cases of middle defect are the same as in case of non-defected cases, except in the $\mathrm{RZ}$ direction. The modal participation with rotational in RZ direction changes from third mode in case of non-defected tube to the third and fourth modes in case of middle defected tube, as shown in Fig. 5. The side defect tends to change the modal participation of first mode from UY\&RX (as in the other cases of non-defected and defected with middle defect) to UX\&RY. In addition, the side defect tends to change modal participation of second mode from UX\&RY to UY\&RX, as presented in Fig. 6 . (b) Armchair CNT $(10,10)$

Table 4 illustrates the effect of defect location on the first ten natural frequencies and the modal participation factors for Armchair $(10,10)$ SWCNTs. It is worth noting that the first and second natural frequencies are equal in their values, but have different modal participation in case of prefect tube (non-defected). The defected conditions show significant changes in the first and second frequencies and their values become unequal. The modal participation is affected in case of side defect; however, the lower defect has no effect on the modal participation of the first two mode shapes.

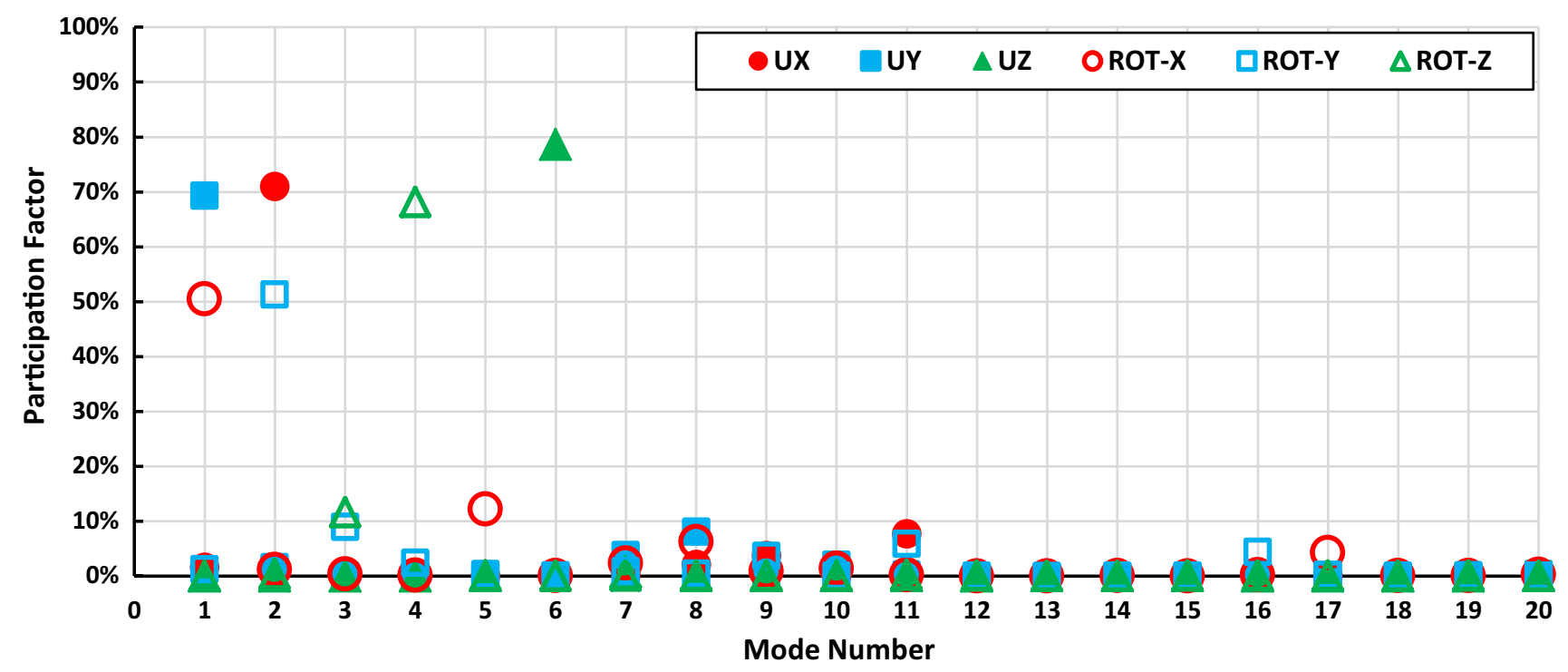

Fig. 5 Modal participation factor for zigzag $(10,0) \mathrm{CNT}$ with middle defect (length $=50 \AA$ ) 


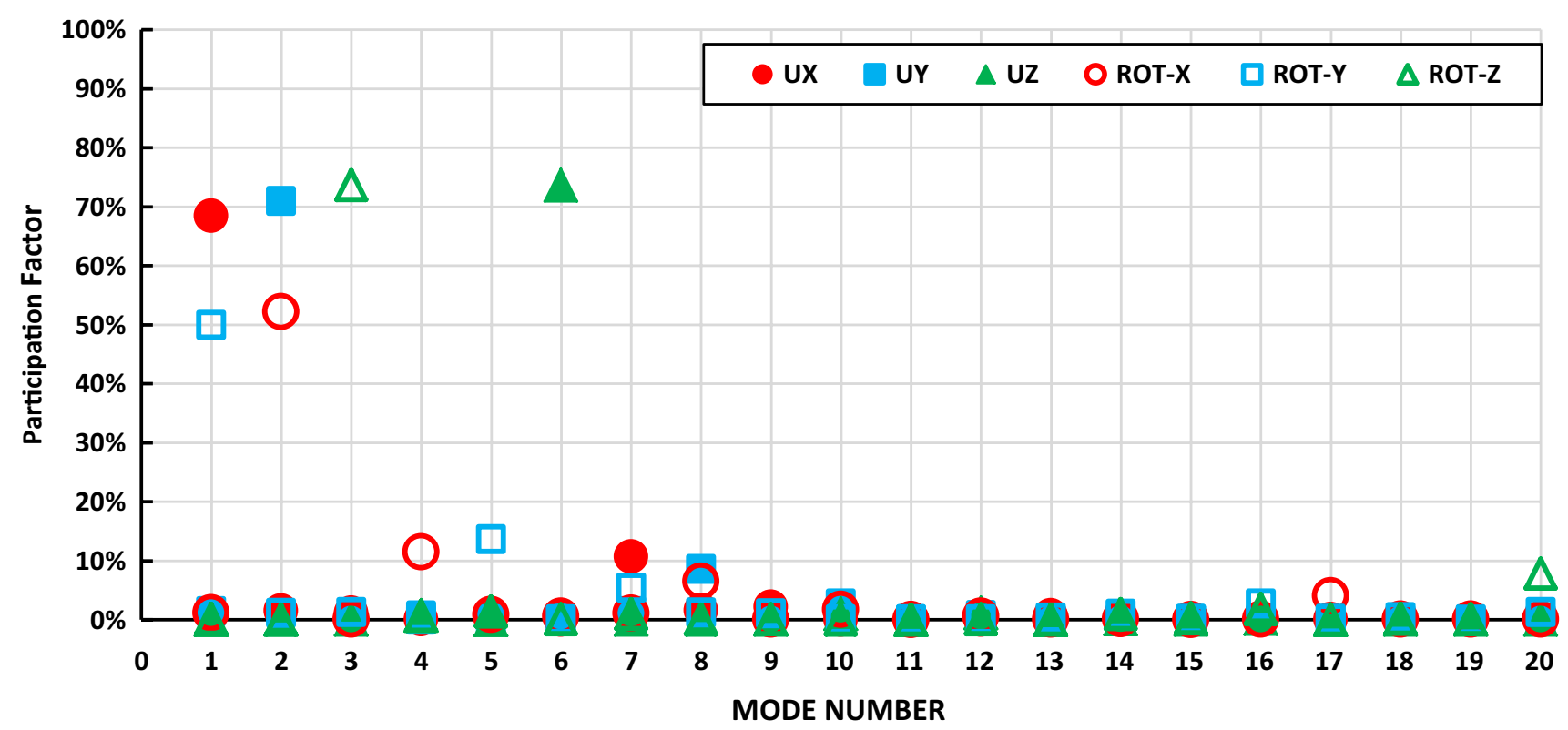

Fig. 6 Modal participation factor for zigzag $(10,0) \mathrm{CNT}$ with side defect (length $=50 \AA$ )

Table 4 First ten frequency values $f(\mathrm{GHz})$ for armchair CNT $(10,10)$ with CNT length $L=50 \AA$

\begin{tabular}{lllllllllll}
\hline & 1 & 2 & 3 & 4 & 5 & 6 & 7 & 8 & 9 \\
\hline Mode of vibration & UX\&RY & UY \&RX & Weak & Weak & RZ & Weak & Weak & Weak & Weak & Weak \\
No defects & 390.67 & 390.67 & 472.72 & 472.73 & 635.40 & 664.53 & 664.62 & 797.86 & 797.86 & 959.96 \\
Mode of vibration & UY & UX & Weak & Weak & RZ & RZ & Weak & RY & RX & Weak \\
& RX & RY & & & & & & & \\
With middle defect & 388.71 & 396.58 & 469.09 & 469.90 & 644.47 & 648.75 & 659.54 & 746.22 & 796.29 & 948.77 \\
Mode of vibration & UX & UY & Weak & Weak & RZ & Weak & Weak & RY & RX \\
& RY & RX & & & & & & Weak \\
With lower defect & 364.61 & 390.60 & 468.32 & 471.02 & 609.84 & 656.58 & 663.40 & 784.15 & 796.54 & 955.86 \\
\hline
\end{tabular}

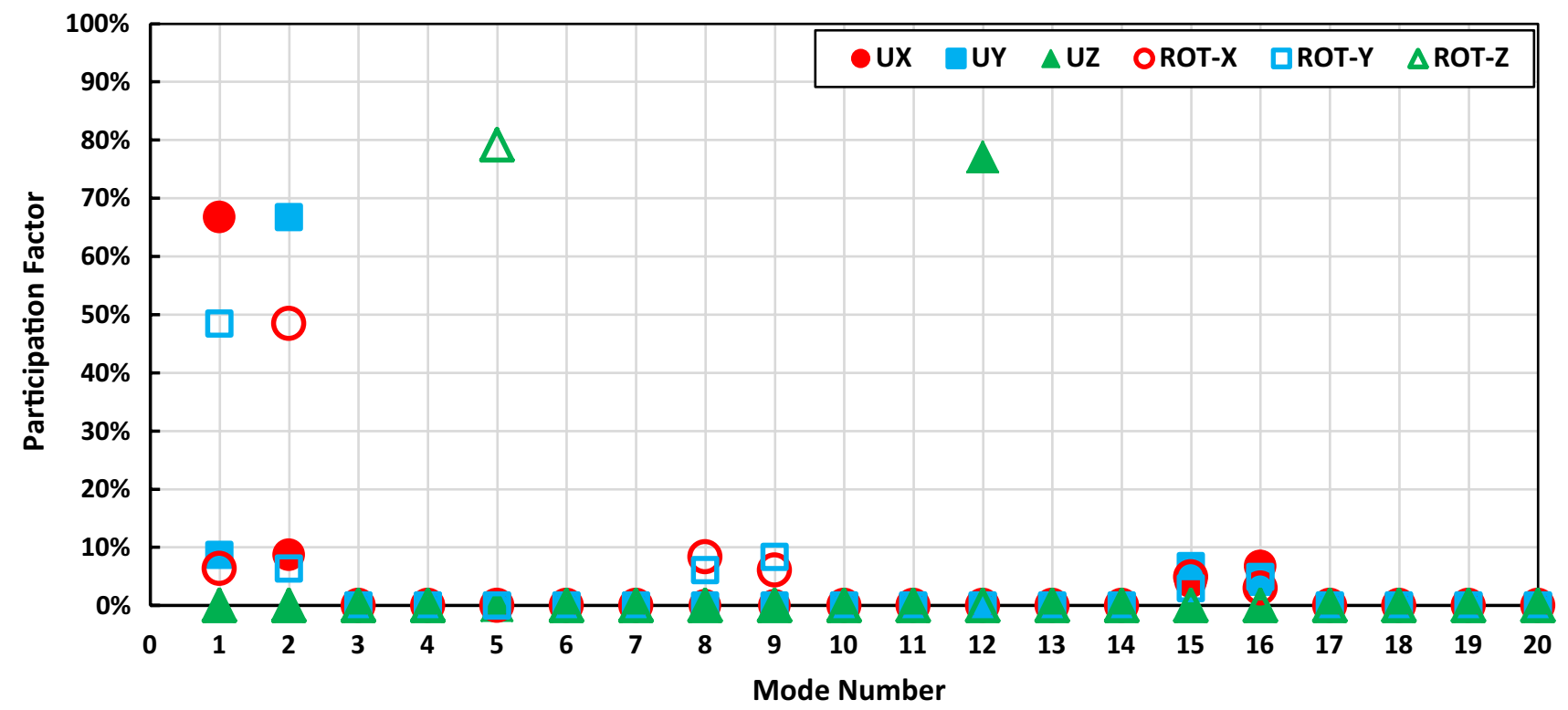

Fig. 7 Modal participation factor for armchair $(10,10)$ CNT without defect (length $=50 \AA$ ) 


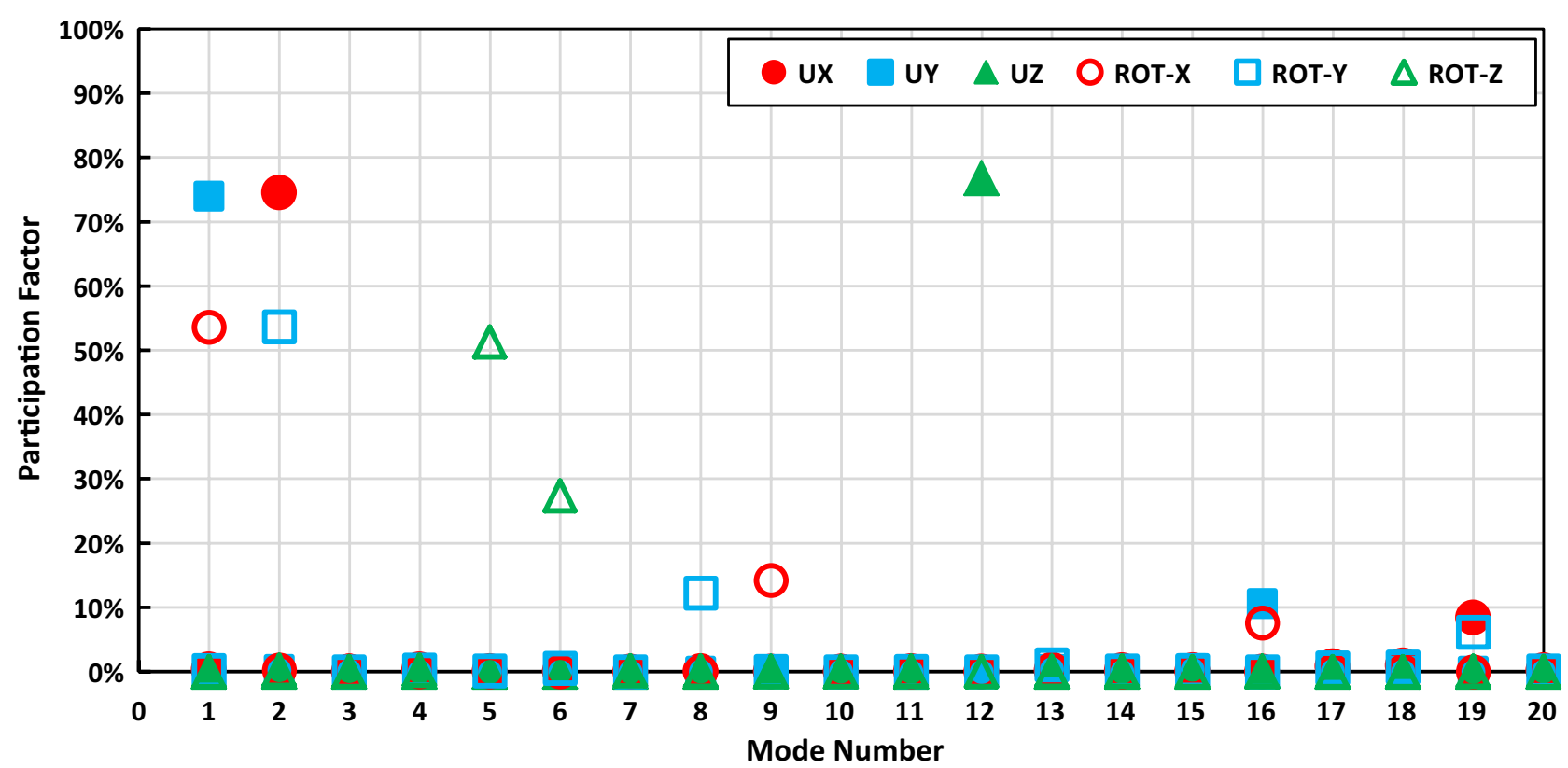

Fig. 8 Modal Participation factor for armchair $(10,10)$ CNT with middle defect (length $=50 \AA$ )

The third and fourth mode shapes do not have modal participation at any direction, which are kept with the same behavior with the middle defect. As shown in Table 4, the middle defect is more significant on the modal participation more than the side defect.

The modal participation factor for the perfect and the two defected tubes are shown in Figs. 7, 8, and 9. In case of non-defected Armchair SWCNTs, the modal participation with displacement in $X$-DIR (UX) is dominant in the first mode. The modal participation with displacement in $Y$-DIR (UY) is dominant in the second mode. In addition, no participation is observed with displacement in $Z$-direction. The modal participation with rotational around $Y$-axis (RY), $x$-axis (RX), and $z$-axis (RZ) are dominant in first, second,

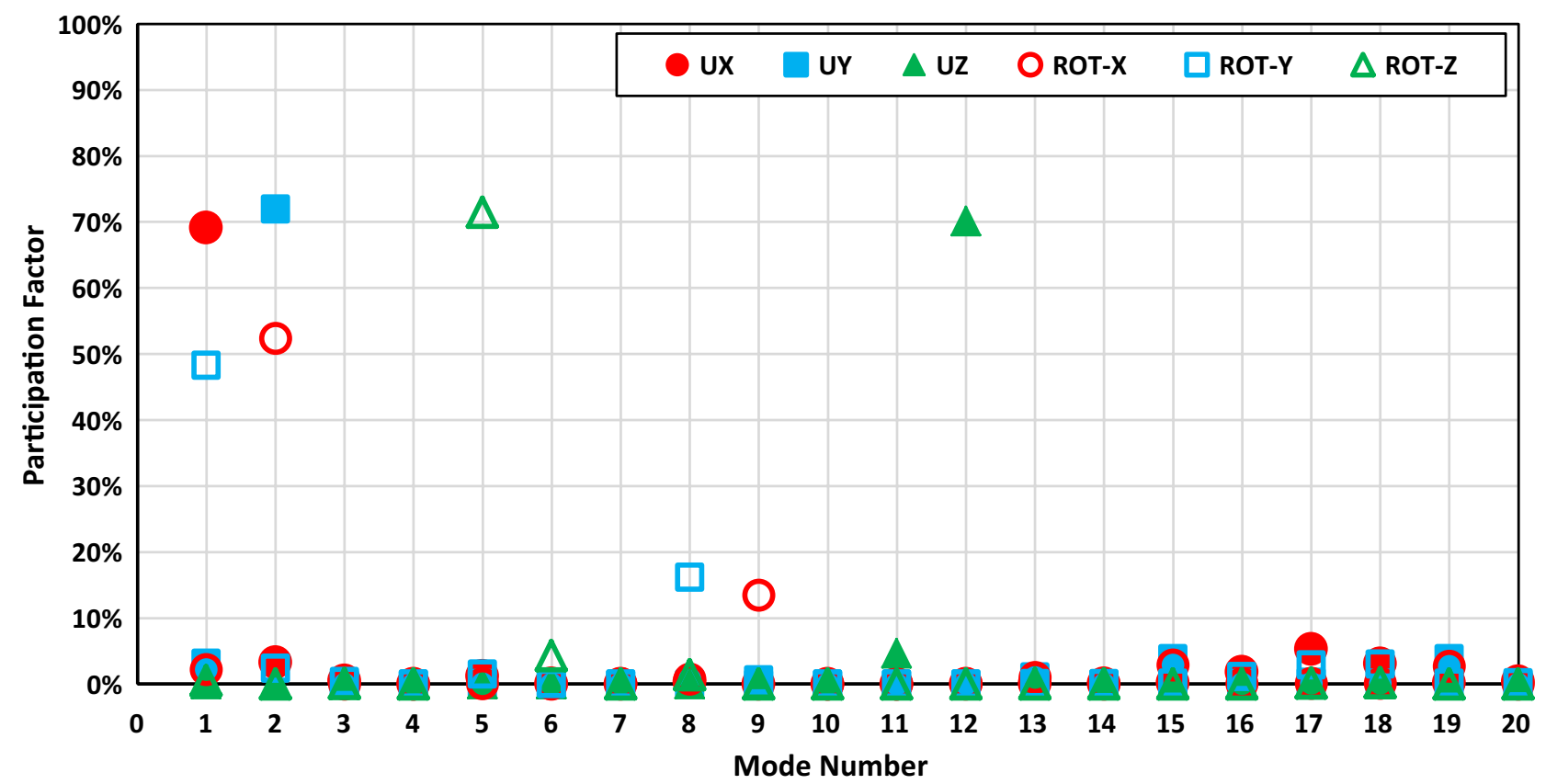

Fig. 9 Modal participation factor for armchair $(10,10)$ CNT with lower defect (length $=50 \AA$ ) 
and fifth mode, respectively. All other modes have neither significant displacement nor rotational modal participations.

The modal participation factors in cases of side defect are the same as in case of non-defected cases, except at the eighth and ninth modes, the side defect created rotational modal participation about $Y$-axis and $X$-axis, respectively. The middle defect has changed the modal participation for all modes except the fifth mode, which is kept with rotational modal participation around $Z$-direction.

\section{Length effects on the defected SWCNT at the middle position}

As concluded from the previous results, the most significant position of the defect is at the middle of the tube, middle defect. Therefore, the effect of SWCNT length on the modal participation factors and natural frequencies are studied in this section for middle defected tubes. Both Zigzag $(10,0)$ and Armchair $(10,10)$ with different tube lengths, $50 \AA, 100$ $\AA$, $150 \AA$, and $180 \AA$ are studied.
The effect of tube length on natural frequencies of Zigzag $(10,0)$ and Armchair $(10,10)$ SWCNT's are presented in Tables 5 and 6, respectively. As concluded, by increasing the NTs lengths, the natural frequencies decrease for defected and non-defected tubes. In addition, the middle defect tends to reduce the stiffness at the modes with bending modal participations in tubes longer than 100 $\AA$. Short tubes with bending modal participation around $X$-direction and with translational modal participation in $Y$-direction shows lower natural frequencies due to middle defects. The defect has less significant effects on the long tubes due to the dominating of the length weakness than the defect weakness. First and second modes of the nondefected tube have similar natural frequencies, and the third and fourth modes have similar natural frequencies as well. The middle defect changes the modal participation of these modes with less significant changes to the natural frequencies for the long tubes.

Table 5 First tenth frequencies (GHz) and active modes for zigzag CNT $(10,0)$ without and with middle defect at different lengths

\begin{tabular}{|c|c|c|c|c|c|c|c|c|c|c|}
\hline & 1 & 2 & 3 & 4 & 5 & 6 & 7 & 8 & 9 & 10 \\
\hline \multicolumn{11}{|l|}{$L=50 \AA$} \\
\hline Mode of vibration & $\begin{array}{l}\text { UY } \\
\& \\
\text { RX }\end{array}$ & $\begin{array}{l}\text { UX } \\
\& \\
\text { RY }\end{array}$ & $\mathrm{RZ}$ & $\mathrm{RX}$ & RY & $U Z$ & $U Y$ & $U X$ & Weak & Weak \\
\hline Without defect & 304.63 & 304.63 & 610.80 & 669.68 & 669.68 & 1036.00 & 1101.20 & 1101.20 & 1223.50 & 1226.10 \\
\hline Mode of vibration & $\begin{array}{l}\text { UY } \\
\& \\
\text { RX }\end{array}$ & $\begin{array}{l}\text { UX } \\
\& \\
\text { RY }\end{array}$ & $\mathrm{RZ}$ & $\mathrm{RZ}$ & $\mathrm{RX}$ & $\mathrm{UZ}$ & Weak & Weak & Weak & Weak \\
\hline $\begin{array}{l}\text { With middle defect } \\
L=100 \AA\end{array}$ & 308.63 & 325.68 & 647.22 & 661.78 & 707.42 & 1066.00 & 1086.90 & 1134.30 & 1155.30 & 1196.20 \\
\hline Mode of vibration & $\begin{array}{l}\text { UY } \\
\text { RX }\end{array}$ & $\begin{array}{l}\text { UX } \\
\text { RY }\end{array}$ & $\mathrm{RX}$ & RY & $\mathrm{RZ}$ & $\begin{array}{l}\text { UY } \\
\text { RX }\end{array}$ & $\begin{array}{l}\text { UX } \\
\text { RY }\end{array}$ & $\mathrm{UZ}$ & Weak & Weak \\
\hline Without defect & 92.14 & 92.14 & 232.73 & 232.74 & 312.39 & 415.88 & 415.88 & 506.93 & 624.76 & 625.87 \\
\hline Mode of vibration & $\begin{array}{l}\text { UY } \\
\text { RX }\end{array}$ & $\begin{array}{l}\text { UX } \\
\text { RY }\end{array}$ & RY & $\mathrm{RX}$ & $\mathrm{RZ}$ & $\begin{array}{l}\text { UY } \\
\text { RX }\end{array}$ & $\begin{array}{l}\text { UX } \\
\text { RY }\end{array}$ & $\mathrm{UZ}$ & Weak & Weak \\
\hline $\begin{array}{l}\text { With middle defect } \\
L=150 \AA\end{array}$ & 88.79 & 93.22 & 227.29 & 232.47 & 316.60 & 398.33 & 419.11 & 513.77 & 547.35 & 623.80 \\
\hline Mode of vibration & $\begin{array}{l}\text { UY } \\
\text { RX }\end{array}$ & $\begin{array}{l}\text { UX } \\
\text { RY }\end{array}$ & $\mathrm{RX}$ & RY & $\mathrm{RZ}$ & $\begin{array}{l}\text { UY } \\
\text { RX }\end{array}$ & $\begin{array}{l}\text { UX } \\
\text { RY }\end{array}$ & Weak & Weak & $\mathrm{UZ}$ \\
\hline Without defect & 43.32 & 43.32 & 114.13 & 114.13 & 209.42 & 212.14 & 212.14 & 330.69 & 330.69 & 339.98 \\
\hline Mode of vibration & $\begin{array}{l}\text { UY } \\
\text { RX }\end{array}$ & $\begin{array}{l}\text { UX } \\
\text { RY }\end{array}$ & RY & $\mathrm{RX}$ & $\begin{array}{l}\text { UY } \\
\text { RX }\end{array}$ & $\mathrm{RZ}$ & $\begin{array}{l}\text { UX } \\
\text { RZ }\end{array}$ & Weak & Weak & $\mathrm{UZ}$ \\
\hline $\begin{array}{l}\text { With middle defect } \\
L=180 \AA\end{array}$ & 42.01 & 43.65 & 113.13 & 114.00 & 204.29 & 210.27 & 213.98 & 321.40 & 329.69 & 343.05 \\
\hline Mode of vibration & $\begin{array}{l}\text { UY } \\
\text { RX }\end{array}$ & $\begin{array}{l}\text { UX } \\
\text { RY }\end{array}$ & $\mathrm{RX}$ & RY & $\begin{array}{l}\text { UY } \\
\text { RX }\end{array}$ & $\begin{array}{l}\text { UX } \\
\text { RY }\end{array}$ & $\mathrm{RZ}$ & Weak & Weak & $\mathrm{UZ}$ \\
\hline Without defect & 30.42 & 30.42 & 81.14 & 81.14 & 152.89 & 152.89 & 174.42 & 241.57 & 241.57 & 283.20 \\
\hline Mode of vibration & $\begin{array}{l}\text { UY } \\
\text { RX }\end{array}$ & $\begin{array}{l}\text { UX } \\
\text { RY }\end{array}$ & RY & $\mathrm{RX}$ & $\begin{array}{l}\text { UY } \\
\text { RX }\end{array}$ & $\begin{array}{l}\text { UX } \\
\text { RY }\end{array}$ & $\mathrm{RZ}$ & Weak & Weak & $\mathrm{UZ}$ \\
\hline With middle defect & 29.59 & 30.61 & 80.71 & 81.09 & 147.61 & 153.31 & 175.80 & 237.51 & 241.09 & 285.32 \\
\hline
\end{tabular}


Table 6 First tenth frequencies (GHZ) and active modes for armchair CNT $(10,10)$ without and with middle defects at different lengths

\begin{tabular}{|c|c|c|c|c|c|c|c|c|c|c|}
\hline & 1 & 2 & 3 & 4 & 5 & 6 & 7 & 8 & 9 & 10 \\
\hline \multicolumn{11}{|l|}{$L=50 \AA$} \\
\hline Mode of vibration & $\begin{array}{l}\text { UX } \\
\text { RY }\end{array}$ & $\begin{array}{l}\text { UY } \\
\text { RX }\end{array}$ & Weak & Weak & $\mathrm{RZ}$ & Weak & Weak & Weak & Weak & Weak \\
\hline Without defect & 390.67 & 390.67 & 472.72 & 472.73 & 635.40 & 664.53 & 664.62 & 797.86 & 797.86 & 959.96 \\
\hline Mode of vibration & $\begin{array}{l}\text { UY } \\
\text { RX }\end{array}$ & $\begin{array}{l}\text { UX } \\
\text { RY }\end{array}$ & Weak & Weak & $\mathrm{RZ}$ & $\mathrm{RZ}$ & Weak & RY & $\mathrm{RX}$ & Weak \\
\hline $\begin{array}{l}\text { With middle defect } \\
L=100 \AA\end{array}$ & 388.71 & 396.58 & 469.09 & 469.90 & 644.47 & 648.75 & 659.54 & 746.22 & 796.29 & 948.77 \\
\hline Mode of vibration & $\begin{array}{l}\text { UX } \\
\text { RY }\end{array}$ & $\begin{array}{l}\text { UY } \\
\text { RX }\end{array}$ & $\mathrm{RZ}$ & RY & $\mathrm{RX}$ & Weak & Weak & Weak & Weak & UZ \\
\hline Without defect & 139.20 & 139.20 & 310.98 & 317.81 & 317.81 & 419.73 & 419.78 & 450.87 & 450.89 & 511.26 \\
\hline Mode of vibration & $\begin{array}{l}\text { UY } \\
\text { RX }\end{array}$ & $\begin{array}{l}\text { UX } \\
\text { RY }\end{array}$ & RY & $\mathrm{RZ}$ & $\mathrm{RX}$ & Weak & Weak & Weak & Weak & Weak \\
\hline $\begin{array}{l}\text { With middle defect } \\
L=150 \AA\end{array}$ & 138.20 & 140.44 & 310.06 & 313.44 & 317.72 & 415.46 & 415.95 & 449.94 & 450.57 & 513.53 \\
\hline Mode of vibration & $\begin{array}{l}\text { UX } \\
\text { RY }\end{array}$ & $\begin{array}{l}\text { UY } \\
\text { RX }\end{array}$ & RY & $\mathrm{RX}$ & $\mathrm{RZ}$ & $\begin{array}{l}\text { UX } \\
\text { RY }\end{array}$ & $\begin{array}{l}\text { UY } \\
\text { RX }\end{array}$ & $\mathrm{UZ}$ & Weak & Weak \\
\hline Without defect & 68.65 & 68.93 & 168.71 & 169.20 & 205.75 & 294.85 & 295.40 & 338.75 & 411.58 & 414.53 \\
\hline Mode of vibration & $\begin{array}{l}\text { UY } \\
\text { RX }\end{array}$ & $\begin{array}{l}\text { UX } \\
\text { RY }\end{array}$ & RY & $\mathrm{RX}$ & $\mathrm{RZ}$ & $\begin{array}{l}\text { UY } \\
\text { RX }\end{array}$ & $\begin{array}{l}\text { UX } \\
\text { RY }\end{array}$ & $\mathrm{UZ}$ & Weak & Weak \\
\hline $\begin{array}{l}\text { With middle defect } \\
L=180 \AA\end{array}$ & 68.37 & 69.06 & 166.97 & 169.15 & 206.80 & 292.38 & 295.88 & 340.48 & 395.29 & 411.56 \\
\hline Mode of vibration & $\begin{array}{l}\text { UX, RY } \\
\text { UY, RX }\end{array}$ & $\begin{array}{l}\text { UY, RX } \\
\text { UX, RY }\end{array}$ & Weak & Weak & $\mathrm{RZ}$ & UX & UY & $\mathrm{UZ}$ & Weak & Weak \\
\hline Without defect & 49.71 & 49.71 & 125.32 & 125.32 & 171.88 & 223.49 & 223.49 & 283.34 & 335.70 & 335.70 \\
\hline Mode of vibration & $\begin{array}{l}\text { UY } \\
\text { RX }\end{array}$ & $\begin{array}{l}\text { UX } \\
\text { RY }\end{array}$ & $R Y$ & $R X$ & $\mathrm{RZ}$ & $\begin{array}{l}\text { UY } \\
\text { RX }\end{array}$ & $\begin{array}{l}\text { UX } \\
\text { RY }\end{array}$ & $\mathrm{UZ}$ & Weak & Weak \\
\hline With middle defect & 49.33 & 49.96 & 124.44 & 125.29 & 172.62 & 221.25 & 224.23 & 284.56 & 325.29 & 335.48 \\
\hline
\end{tabular}

\section{Conclusion}

In this article, a continuum mechanics that is derived from the basis molecular simulation is adopted to investigate vibrational behaviors of fixed-fixed SWCNTs with vacancy defects at different lengths. A numerical finite-element analysis with the nanotube software modeler is exploited to study the problem. Effects of vacancy position and tube length on the natural frequencies, mode shapes, and modal participation factors are presented for both fixed-fixed-supported zigzag and armchair orientations. Conclusions from this study can be summarized as follows:

1. The defects tend to decrease the natural frequencies of short tubes either zigzag or armchair SWCNTs if the defect is in the middle or at near to the fixed edge. In this case, the reduction in overall stiffness is more than the reduction in overall mass of SWCNT.

2. The defect tends to increase the natural frequencies, if its position is not affecting the modal participation, I which, the reduction in overall mass is higher than the reduction in stiffness.
3. Twelve modes are satisfied to describe accurately the vibrational behaviors of zigzag $(10,0)$ SWCNTs. However, 20 modes should be developed in case of armchair $(10,10)$ to study its vibrational behaviors.

4. Increasing of SWCNT length tends to decrease the natural frequencies of perfect CNTs.

5. The tube length and defects may activate and deactivate mode shapes.

6. Mode shapes in $X$-DIR and $Y$-DIR are significant in lower frequencies. However, modes in Z-DIR are more pronounced at higher vibrational frequencies.

Open Access This article is distributed under the terms of the Creative Commons Attribution 4.0 International License (http://creativeco mmons.org/licenses/by/4.0/), which permits unrestricted use, distribution, and reproduction in any medium, provided you give appropriate credit to the original author(s) and the source, provide a link to the Creative Commons license, and indicate if changes were made. 


\section{References}

Agwa MA, Eltaher MA (2016) Vibration of a carbyne nanomechanical mass sensor with surface effect. Appl Phys A 122(4):335

Ahmadabadi HN, Ghafouri-Khosrowshahi A, Ahmadimoghaddam D, Nili-Ahmadabadi A (2018) Effect of thermal dependency of diameter on density of states for zigzag carbon nano-tubes. J Nano Res 55:1-10

Ahouel M, Houari MSA, Bedia EA, Tounsi A (2016) Size-dependent mechanical behavior of functionally graded trigonometric shear deformable nanobeams including neutral surface position concept. Steel Compos Struct 20(5):963-981

Bakhadda B, Bouiadjra MB, Bourada F, Bousahla AA, Tounsi A, Mahmoud SR (2018) Dynamic and bending analysis of carbon nanotube-reinforced composite plates with elastic foundation. Wind Struct 27(5):311-324

Belkorissat I, Houari MSA, Tounsi A, Bedia EA, Mahmoud SR (2015) On vibration properties of functionally graded nanoplate using a new nonlocal refined four variable model. Steel Compos Struct 18(4):1063-1081

Bellifa H, Benrahou KH, Bousahla AA, Tounsi A, Mahmoud SR (2017) A nonlocal zeroth-order shear deformation theory for nonlinear postbuckling of nanobeams. Struct Eng Mech 62(6):695-702

Besseghier A, Houari MSA, Tounsi A, Mahmoud SR (2017) Free vibration analysis of embedded nanosize FG plates using a new nonlocal trigonometric shear deformation theory. Smart Struct Syst 19(6):601-614

Bianco MJ, Könke C, Habtemariam A, Zabel V (2018) Exact finite element formulation in generalized beam theory. Int $\mathbf{J} \mathrm{Adv}$ Struct Eng 10(3):295-323

Bouadi A, Bousahla AA, Houari MSA, Heireche H, Tounsi A (2018) A new nonlocal HSDT for analysis of stability of single layer graphene sheet. Adv Nano Res 6(2):147-162

Bouafia K, Kaci A, Houari MSA, Benzair A, Tounsi A (2017) A nonlocal quasi-3D theory for bending and free flexural vibration behaviors of functionally graded nanobeams. Smart Struct Syst 19(2):115-126

Bounouara F, Benrahou KH, Belkorissat I, Tounsi A (2016) A nonlocal zeroth-order shear deformation theory for free vibration of functionally graded nanoscale plates resting on elastic foundation. Steel Compos Struct 20(2):227-249

Chaht FL, Kaci A, Houari MSA, Tounsi A, Bég OA, Mahmoud SR (2015) Bending and buckling analyses of functionally graded material (FGM) size-dependent nanoscale beams including the thickness stretching effect. Steel Compos Struct 18(2):425-442

Charlier JC (2002) Defects in carbon nanotubes. Acc Chem Res 35(12):1063-1069

Eltaher MA, Agwa MA (2016) Analysis of size-dependent mechanical properties of CNTs mass sensor using energy equivalent model. Sens Actuators A 246:9-17

Eltaher MA, El-Borgi S, Reddy JN (2016) Nonlinear analysis of sizedependent and material-dependent nonlocal CNTs. Compos Struct 153:902-913

Eltaher MA, Agwa M, Kabeel A (2018a) Vibration analysis of material size-dependent CNTs using energy equivalent model. J Appl Comput Mech 4(2):75-86

Eltaher MA, Mohamed N, Mohamed S, Seddek LF (2018b) Postbuckling of curved carbon nanotubes using energy equivalent model. J Nano Res 1:1-11 accepted

Eltaher MA, Almalki TA, Ahmed KIE, Almitani KH (2019) Characterization and behaviors of single walled carbon nanotube by equivalent continuum mechanics approach. Adv Nano Res 7(1):39-49

Esbati AH, Irani S (2018) Probabilistic mechanical properties and reliability of carbon nanotubes. Arch Civ Mech Eng 18(2):532-545
Gajbhiye SO, Singh SP (2015) Vibration characteristics of open-and capped-end single-walled carbon nanotubes using multi-scale analysis technique incorporating Tersoff-Brenner potential. Acta Mech 226(11):3565-3586

Hamza-Cherif R, Meradjah M, Zidour M, Tounsi A, Belmahi S, Bensattalah T (2018) Vibration analysis of nano beam using differential transform method including thermal effect. J Nano Res 54:1-14

Kadari B, Bessaim A, Tounsi A, Heireche H, Bousahla AA, Houari MSA (2018) Buckling analysis of orthotropic nanoscale plates resting on elastic foundations. J Nano Res 55:42-56

Karami B, Janghorban M, Tounsi A (2017) Effects of triaxial magnetic field on the anisotropic nanoplates. Steel Compos Struct 25(3):361-374

Karami B, Janghorban M, Tounsi A (2018a) Variational approach for wave dispersion in anisotropic doubly-curved nanoshells based on a new nonlocal strain gradient higher order shell theory. Thin Walled Struct 129:251-264

Karami B, Janghorban M, Tounsi A (2018b) Nonlocal strain gradient 3D elasticity theory for anisotropic spherical nanoparticles. Steel Compos Struct 27(2):201-216

Khetir H, Bouiadjra MB, Houari MSA, Tounsi A, Mahmoud SR (2017) A new nonlocal trigonometric shear deformation theory for thermal buckling analysis of embedded nanosize FG plates. Struct Eng Mech 64(4):391-402

Krishnan A, Dujardin E, Ebbesen TW, Yianilos PN, Treacy MMJ (1998) Young's modulus of single-walled nanotubes. Phys Rev B 58(20):14013

Ma Y, Lehtinen PO, Foster AS, Nieminen RM (2004) Magnetic properties of vacancies in graphene and single-walled carbon nanotubes. New J Phys 6(1):68

Mielke SL, Troya D, Zhang S, Li JL, Xiao S, Car R, Belytschko T (2004) The role of vacancy defects and holes in the fracture of carbon nanotubes. Chem Phys Lett 390(4-6):413-420

Mokhtar Y, Heireche H, Bousahla AA, Houari MSA, Tounsi A, Mahmoud SR (2018) A novel shear deformation theory for buckling analysis of single layer graphene sheet based on nonlocal elasticity theory. Smart Struct Syst 21(4):397-405

Mouffoki A, Bedia EA, Houari MSA, Tounsi A, Mahmoud SR (2017) Vibration analysis of nonlocal advanced nanobeams in hygro-thermal environment using a new two-unknown trigonometric shear deformation beam theory. Smart Struct Syst 20(3):369-383

Rappé AK, Casewit CJ, Colwell KS, Goddard Iii WA, Skiff WM (1992) UFF, a full periodic table force field for molecular mechanics and molecular dynamics simulations. J Am Chem Soc 114(25):10024-10035

Salvetat JP, Bonard JM, Thomson NH, Kulik AJ, Forro L, Benoit W, Zuppiroli L (1999) Mechanical properties of carbon nanotubes. Appl Phys A 69(3):255-260

Shahabodini A, Ansari R, Darvizeh M (2018) Atomistic-continuum modeling of vibrational behavior of carbon nanotubes using the variational differential quadrature method. Compos Struct 185:728-747

Shokrieh MM, Rafiee R (2010) Prediction of Young's modulus of graphene sheets and carbon nanotubes using nanoscale continuum mechanics approach. Mater Des 31(2):790-795

Soltani P, Kassaei A, Taherian MM, Farshidianfar A (2012) Vibration of wavy single-walled carbon nanotubes based on nonlocal Euler Bernoulli and Timoshenko models. Int J Adv Struct Eng 4(1):3

Tahouneh V, Mashhadi MM, Naei MH (2016) Finite element and micromechanical modeling for investigating effective material properties of polymer-matrix nanocomposites with microfiber, reinforced by CNT arrays. Int J Adv Struct Eng 8(3):297-306 
Vila J, Fernández-Sáez J, Zaera R (2018) Reproducing the nonlinear dynamic behavior of a structured beam with a generalized continuum model. J Sound Vib 420:296-314

Wang Q, Varadan VK (2006) Wave characteristics of carbon nanotubes. Int J Solids Struct 43(2):254-265

Wu Y, Zhang X, Leung AYT, Zhong W (2006) An energy-equivalent model on studying the mechanical properties of single-walled carbon nanotubes. Thin Walled Struct 44(6):667-676

Yazid M, Heireche H, Tounsi A, Bousahla AA, Houari MSA (2018) A novel nonlocal refined plate theory for stability response of orthotropic single-layer graphene sheet resting on elastic medium. Smart Struct Syst 21(1):15-25
Zemri A, Houari MSA, Bousahla AA, Tounsi A (2015) A mechanical response of functionally graded nanoscale beam: an assessment of a refined nonlocal shear deformation theory beam theory. Struct Eng Mech 54(4):693-710

Publisher's Note Springer Nature remains neutral with regard to jurisdictional claims in published maps and institutional affiliations. 